\title{
Numerical Simulation of Mutually Embedded Settlement in Miscellaneous Fill
}

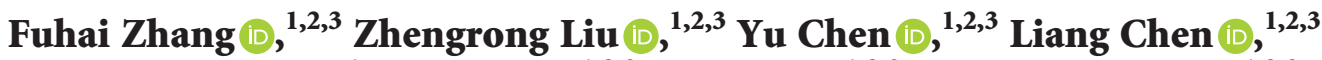 \\ Xianwen Huang $\mathbb{D}^{4}{ }^{4}$ Yanhui Bai, ${ }^{1,2,3}$ Chong Shi, ${ }^{1,2,3}$ and Tianbao Zhou ${ }^{1,2,3}$ \\ ${ }^{1}$ Research Institute of Geotechnical Engineering, Hohai University, Nanjing 210098, China \\ ${ }^{2}$ Key Laboratory of Ministry of Education for Geomechanics and Embankment Engineering, Hohai University, \\ Nanjing 210098, China \\ ${ }^{3}$ Engineering Research Center of Dredging Technology of Ministry of Education, Hohai University, Nanjing 210098, China \\ ${ }^{4}$ Department of Civil and Architecture Engineering, Jiangsu University of Science and Technology, Zhenjiang, China
}

Correspondence should be addressed to Fuhai Zhang; fhzhang@hhu.edu.cn and Yu Chen; 191304010023@hhu.edu.cn

Received 6 November 2020; Revised 1 December 2020; Accepted 11 December 2020; Published 21 December 2020

Academic Editor: Zhigang Tao

Copyright ( 92020 Fuhai Zhang et al. This is an open access article distributed under the Creative Commons Attribution License, which permits unrestricted use, distribution, and reproduction in any medium, provided the original work is properly cited.

\begin{abstract}
Embedding soft soil particles with high moisture content into miscellaneous fill with large pores under overlying loads is easy. It produces mutually embedded settlement, which is an important component of total foundation settlement during calculation. In this study, influences of interface friction on mutually embedded settlement, particle displacement, pore and contact characteristics, and mutually embedded development laws were analysed by using the particle flow method. Research results demonstrate that mutually embedded settlement decreases first and then stabilizes with the increase in contact friction factor and continuously attenuates with normal stiffness. Under the loads, particles at the contact surface move downward and squeeze surrounding particles laterally, thus causing particles to slide at the miscellaneous fill channel upward. Consequently, porosity of particles in miscellaneous fill channel increases. The force chain at the contact surface inclines around, while that at the miscellaneous fill channel presents approximately horizontal distribution. Compared with 35 and $45 \mathrm{~mm}$ particles, the mutually embedded settlement of 15 and $25 \mathrm{~mm}$ particles is slightly increased with loads. Particle size can relieve the influences of loads on mutual embedding. When particle size is larger than $25 \mathrm{~mm}$, loads can significantly influence mutual embedding. Research conclusions can provide a reasonable theoretical foundation for calculating or predicting settlement of miscellaneous fill-soft soil composite foundation.
\end{abstract}

\section{Introduction}

Urban construction and reconstruction will produce a considerable amount of miscellaneous fill, which is characteristic of a large natural density range, loose structure, large compressive deformation, and low strength. Miscellaneous fill is significantly different from uniform soil in terms of mechanical properties [1-3]. In foundations with miscellaneous fill and soft soil, embedding miscellaneous fill particles into soft soil under overlying loads is easy (Figure 1). This phenomenon may decrease pores among miscellaneous fill particles and thereby cause foundation settlement. Settlement analysis and prediction of miscellaneous fill composite foundation have become research hotspots in geotechnical engineering.

Considering the basic properties of miscellaneous fill, scholars in China and foreign countries have discussed its mechanical properties through laboratory experiments. Some experimental instruments, such as large- and middlesized triaxial apparatus [4-10], shear apparatus [11, 12], and horizontal push-shear text [13-16], are commonly used. Existing associated studies focus on moisture content and strength characteristics of miscellaneous fill $[17,18]$, compression [19], permeability, and particle composition. Layerwise summation method is still applied to determine the final settlement of miscellaneous fill foundation in practical 


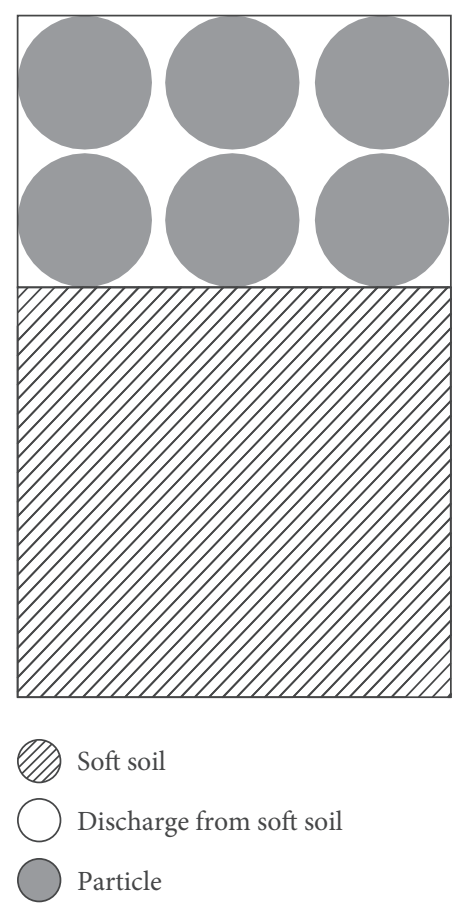

(a)

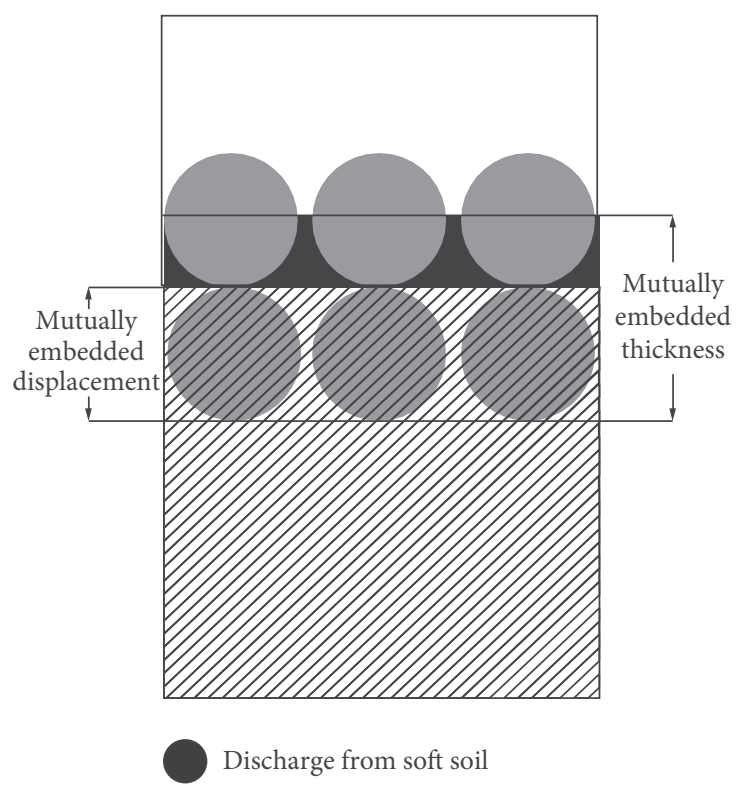

(b)

Figure 1: An example of mutual embedding of soft soil and miscellaneous fill particles: (a) before mutual embedding; (b) after mutual embedding.

engineering [20-22]. Alternatively, settlement of miscellaneous fill foundation is predicted through finite element simulation and other numerical simulation methods [23-26]. Variation laws of foundation coefficient and degree of consolidation are mainly discussed for bearing capacity of miscellaneous fill foundation through load tests [27-34].

Existing studies on settlement of miscellaneous fill foundation currently focus on single aspects. A few methods are available to predict settlement of miscellaneous fill foundation with soft soil layer effectively. Therefore, influencing laws of interface friction on mutually embedded settlement of miscellaneous fill and soft soil, as well as basic characteristics of soft soil particle displacement, porosity, and contact in the mutual embedding process, were investigated by particle flow method. On this basis, causes of miscellaneous fill-soft soil mutual embedding and relevant microscopic mechanism were disclosed. Research conclusions provide reasonable theoretical references to predict settlement of miscellaneous fill-soft soil composite foundation.

\section{Model Construction and Implementation Method}

Mutual embedding is a phenomenon in which soft soil particles embed into pores of particles under loads. Particle displacement at the occurrence of mutual embedding is relatively high. Miscellaneous fill and soft soil particles produce dislocation on spatial position and lead to discontinuous deformation. Particle flow method is unrestricted by deformation volume and can process mechanical problems of discontinuous media. The particle flow method not only effectively simulates discontinuous phenomena, such as cracking and separation of media, but also reflects the mechanism, process, and outcome of soil deformation. Therefore, this method was applied to study the mutual embedding phenomenon in the present study $[35,36]$.

2.1. Construction of Models. The frequent use of cylinder samples in laboratory tests is an axial symmetric problem. In this study, the axial symmetric problem is simplified into a two-axis problem. A two-dimensional plane model was constructed to simulate and analyse formation mechanism and universal law of mutual embedding under the assistance of particle flow PFC2D. The simplified chart of miscellaneous fill particles is shown in Figure 2. Figure 2(a) is the top view of vertically arranged miscellaneous fill particles, and Figure 2(b) is the profile of the plane line. In the profile, the graph diameter is equal to particle diameter. Meanwhile, pore channels, which form vertical particles with equal pore channels, are also available. Channels formed by different sizes of miscellaneous fill particles have different sizes. The relationship between channel size $(L)$ and particle size of miscellaneous fill $(R)$ is determined according to geometric relationship to identify the position relations of miscellaneous fill particles in the model.

$$
L=(2 \sqrt{2}-2) R .
$$

In the aforementioned formula, $L$ is the minimum width of miscellaneous fill channel; $R$ is the radius of miscellaneous fill particles. 


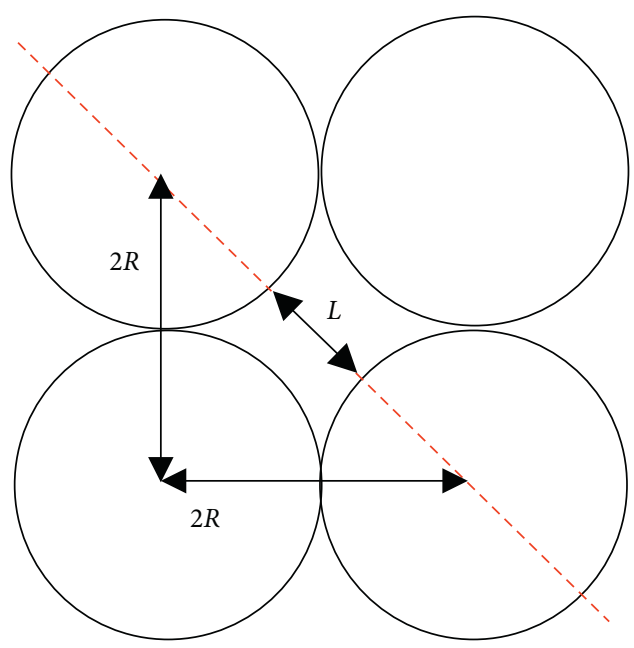

(a)

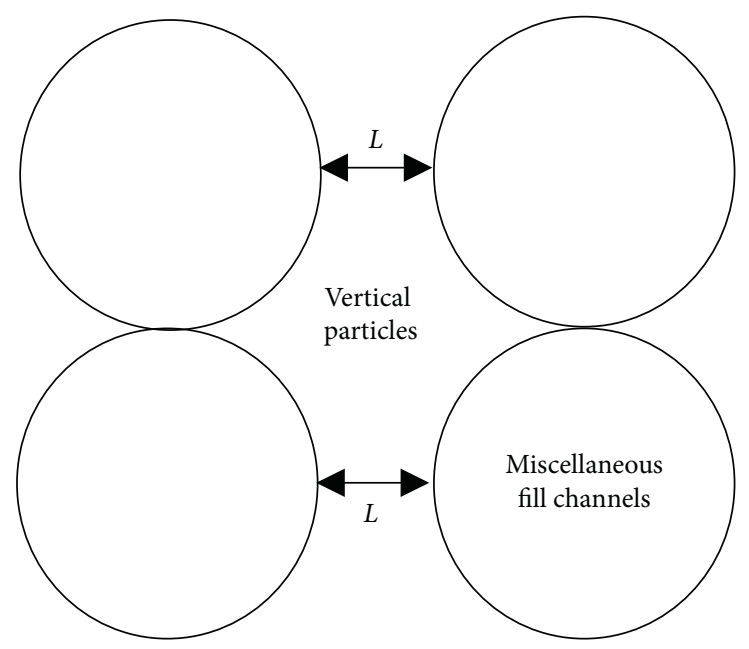

(b)

Figure 2: Channels formed by miscellaneous fill particles. (a) Top view. (b) Profile.

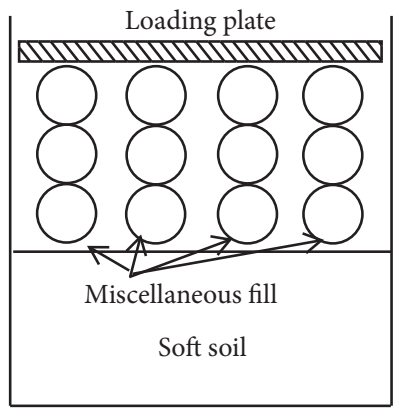

(a)

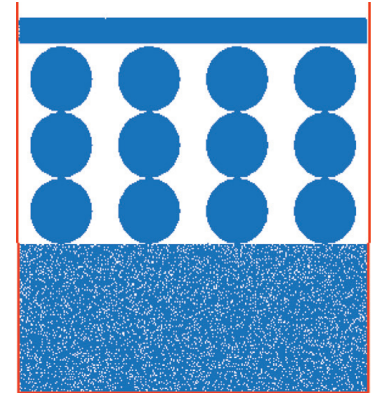

(b)

Figure 3: Structure of the model.

A numerical model for mutual embedding test was constructed based on the aforementioned analysis (Figure 3). The bottom is filled with soft soil particles (ball). Particle size ranges from $0.5 \mathrm{~mm}$ to $1 \mathrm{~mm}$, and particles are in uniform distribution. Height of soft soil particles is $8 \mathrm{~cm}$ and comprises 7416 balls. The upper layer is filled with miscellaneous fill particles. Particle size is equal to particle size in laboratory tests $(15-45 \mathrm{~mm})$. In the numerical test, all miscellaneous fill particles are replaced by the same clump. The number of vertical particles is four, and a single vertical particle is composed of three particles (Figure 3). Rigid walls are used as boundaries. These boundaries are kept $L / 2$ away from the interface of miscellaneous fill particles, meeting the distance relationship among different vertical particles. A loading plate (clump) is found on the top of miscellaneous fill particles. Different densities are given to the loading plate to provide different constant loads.

A simulation test on mutual embedding of miscellaneous fill and soft soil was conducted based on the constructed model. Steps of the simulation test are introduced as follows. (1) Contact model, contact parameters, and gravity are endowed to miscellaneous fill and soft soil particles to balance the model under dead loads. (2) According to the area of loading plate, different densities are provided to the loading plate (in this study, area of the loading plate is $2.74 \times 10^{-3} \mathrm{~m}^{2}$ and density is $7.8 \times 10^{3} \mathrm{~kg} / \mathrm{m}^{3}$; other loads can be inferred in the same way). With the gradual application of loads, 25,50 , and $100 \mathrm{kPa}$ were applied in 25,50 , and 100 times, respectively. A total of 500 time steps were circulated under each load. The loading ended at 60,000 time steps. The size of mutually embedded settlement was also recorded every 500 time steps. The mutually embedded settlement was the product of mutually embedding thickness and porosity. The mutually embedding thickness is the difference between the top and the lowest position of soft soil particles in miscellaneous fill channels. The mean of mutually embedding thickness of three channels was chosen as the final mutually embedding thickness.

2.2. Parameter Calibration. The aforementioned numerical model involves two materials (particles and boundary walls) and four contact types (ball-ball contact between soft soil particles, ball-pebble contact between soft soil and miscellaneous fill particles, ball-facet contact between soft soil particles and boundary walls, and pebble-pebble contact 
between the loading plate and miscellaneous fill particles). The ball-ball contact model applies the antirolling linear contact model, while the remaining contact models (ballpebble, ball-facet, and pebble-pebble) applied the linear models. In this numerical simulation, the contact parameters are adjusted continuously and compared with laboratory test. When the two results are consistent, the contact parameters are determined, as shown in Table 1.

Taking the interpenetrating displacement of $35 \mathrm{~mm}$ particle size as an example, Figure 4 shows the comparison between the numerical simulation results and the experimental parameters under the selected parameters. It can be seen from the figure that the numerical simulation curve is consistent with the experimental curve, indicating that the parameter calibration is effective.

\section{Results}

3.1. Effects of Microparameters of Particles on Mutually Embedded Settlement. Numerical test based on particle flow is conducted to reflect macrochanges in materials through the general motion trail of particles, which is restricted by microparameters of particles. Many types of microparameters, including stiffness, friction coefficient, damping, modulus, and strength, are available. In the model, soft soil particles applied the rolling resistance linear contact model, in which changes in stiffness and friction coefficient can significantly influence simulation results. Therefore, influences of stiffness and friction coefficient on mutually embedded settlement are analysed in this section.

\subsubsection{Effects of Stiffness on Mutually Embedded Settlement.} The simulated relation curves of stiffness and friction coefficient with mutually embedded settlement when particle size is $25 \mathrm{~mm}$ and load is $100 \mathrm{kPa}$ are shown in Figure 4. In Figure 5(a), mutually embedded settlement attenuates in the nonlinear pattern with the increase in normal stiffness. Given the same contact friction coefficient, the maximum static friction at contact interface may increase with contact stiffness. Under this circumstance, mutually embedded settlement decreases with the increase in contact stiffness. When the contact stiffness further increases, the maximum static friction force at contact interface becomes higher than the interparticle maximum static friction force and develops a weak surface between soft soil particles. In this case, contact stiffness influences mutually embedded settlement.

3.1.2. Influences of Friction Coefficient on Mutually Embedded Settlement. Figure 5(b) shows that mutually embedded settlement decreases first and then stabilizes with the increase in friction coefficient. A nonlinear relationship exists between mutually embedded settlement and friction coefficient. When the friction coefficient is $0-0.45$, mutually embedded settlement drops sharply. When friction coefficient exceeds 0.45 , mutually embedded settlement remains constant. In the numerical test, the friction coefficient of soft soil particles is 0.45 , which is close to that at the turning point of the relation curves. When soft soil particles are embedded into miscellaneous fill channel, these particles may produce friction effects with miscellaneous fill particles. When contact friction coefficient is lower than the interparticle friction coefficient, the maximum static friction force at the contact surface of soft soil and miscellaneous fill particles is smaller than the interparticle maximum static friction force. At the occurrence of mutual embedding, soft soil particles in miscellaneous fill channel may slide along the contact surface. Therefore, the interface sliding friction force increases, and the mutually embedded settlement declines as the contact friction coefficient approaches the interparticle friction coefficient. When contact friction coefficient is higher than interparticle friction coefficient, a weak surface of soft soil particles is observed. At this moment, mutually embedded settlement remains the same with the increase in contact friction coefficient.

\subsection{Basic Characteristics of Mutual Embedding}

\subsubsection{Particle Displacement during Mutual Embedding.} The maximum mutually embedded settlement is achieved under $100 \mathrm{kPa}$ and approximately 15,000 time steps. Considering that mutually embedded settlement slightly changes in follow-up time steps, vertical displacements of particles under four time steps $(2500,5000,10,000$, and 15,000) were chosen to study particle displacement characteristics during mutual embedding. Vertical displacements of particles under different time steps are shown in Figure 6, in which particles with an upward vertical displacement higher than zero are expressed in gray. The entire soft soil particles are compressed at 2500 time steps, and only superficial soft soil particles develop displacement. The contact surface displacement between miscellaneous fill and soft soil particles reaches the peak. Particles at the contact surface are still compressed at 5000 time steps, and the vertical displacement of a few particles at miscellaneous fill channel is higher than zero. This finding implies the occurrence of mutual embedding. The number of soft soil particles with displacement higher than zero is increased at 10,000 time steps, and the displacement at the contact surface is relatively evident. Moreover, the displacement diffuses around. Soft soil particles further move upward at 15,000 time steps, while soft soil particles adhered onto the surface of miscellaneous fill particles are kept compressed. Based on displacements at different time steps, particles at contact surface may squeeze particles in miscellaneous fill channel to produce an upward displacement during the development of downward displacement. Mutual embedding is the consequence of relative movement between soft soil and miscellaneous fill particles.

3.2.2. Pore Characteristics of Particles during Mutual Embedding. Measuring circles are set in Figure 7 because the model is symmetric. Statistical analysis on porosity of particles in the region of measuring circles was conducted to obtain the porosity contour line of soft soil particles in Figure 8. On this basis, pore characteristics of particles during mutual embedding at $50 \mathrm{kPa}$ were investigated. Considering that the first row of measuring circles may 
TABLE 1: Contact parameters of particle materials.

\begin{tabular}{lcc}
\hline & Density $\left(\mathrm{kg} / \mathrm{m}^{3}\right)$ & 1800 \\
& Normal stiffness $(\mathrm{N} / \mathrm{m})$ & $4 e^{5}$ \\
Ball-ball & Shear stiffness $(\mathrm{N} / \mathrm{m})$ & $4 e^{5}$ \\
& Friction coefficient & 0.45 \\
& Rolling resistance coefficient & 0.45 \\
& Normal clinical damping ratio & 0.5 \\
& Shear clinical damping ratio & 0.5 \\
\hline \multirow{3}{*}{ Ball-pebble } & Normal stiffness $(\mathrm{N} / \mathrm{m})$ & $5 e^{5}$ \\
& Shear stiffness $(\mathrm{N} / \mathrm{m})$ & $5 e^{5}$ \\
Ball-facet & Friction coefficient & 0.3 \\
\hline & Normal stiffness $(\mathrm{N} / \mathrm{m})$ & $1 e^{6}$ \\
Pebble-pebble & Shear stiffness $(\mathrm{N} / \mathrm{m})$ & $1 e^{6}$ \\
& Friction coefficient & 0.3 \\
\hline
\end{tabular}

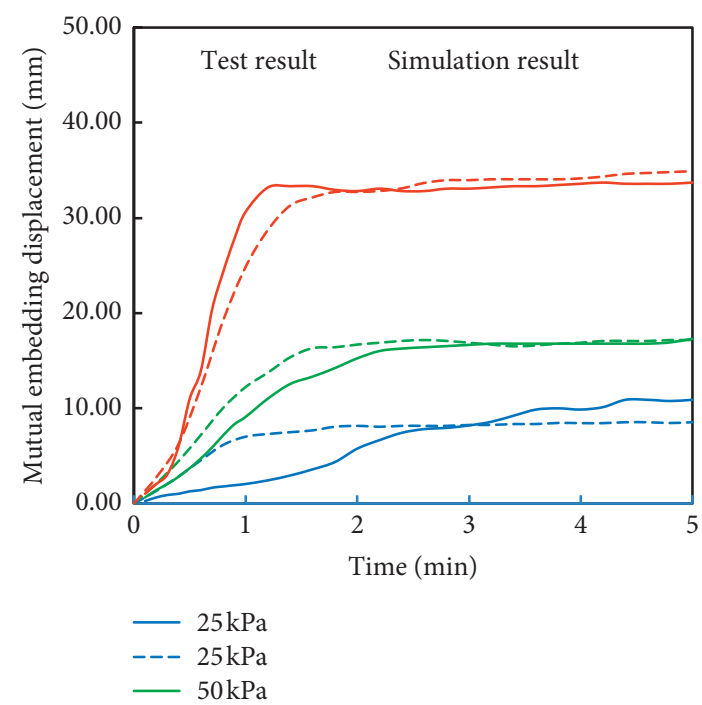

Figure 4: Comparison between simulation and test results.

overlap with miscellaneous fill particles after 10,000 time steps in the test, only porosity distributions at 2500 and 7500 time steps were analysed. At 2500 time steps, the space between contour lines is relatively uniform, and porosity is negatively related to depth. The porosities at contact surface and miscellaneous fill channel are similar and slightly lower than those before loading. Particles are also compressed under this circumstance. At 7500 time steps, the upper contour lines are relatively dense, while the lower contour lines are relatively sparse. A high density of contour lines leads to quick changes in porosity. Evidently, particle porosity at miscellaneous fill channel considerably varies, while that at contact surface slightly changes. By comparing porosities at 2500 time steps, changes in porosity are mainly manifested at the upper position. With the increase in time steps, porosity at miscellaneous fill channel sharply increases, while that at contact surface slightly changes. This finding demonstrates that particles in miscellaneous fill channel slide with the occurrence of mutual embedding. Position state of particles at 10,000 time steps is shown in
Figure 8(c). Particles at miscellaneous fill channel are sparse, but those at contact surface are dense. Therefore, miscellaneous fill particles may squeeze soft soil particles under loads. The loads in the early stage are insufficient to overcome interparticle friction, and particles hardly produce dislocation, thus leading to slight changes in porosity. With the further transmission of loads, particles at the contact surface become tight and squeeze surrounding particles. As a result, particles at miscellaneous fill channel slide upward, and porosity in the miscellaneous fill channel increases accordingly.

\subsubsection{Changes of Intraparticle Contact Force during Mutual} Embedding. Intraparticle force chain distribution under different time steps is shown in Figure 9. The force chain is vertically downward in the beginning. At 2500 time steps, the force chain on the contact surface of soft soil and miscellaneous fill particles is concentrated and begin to skew toward two sides. The contact surface with stress concentration develops a slight downward deformation. Moreover, the force chain develops from the initial stress contact point around. With the increase in time steps, the force chain further develops and becomes dense. The force chain below particles begins to develop and transmits approximately vertically downward, accompanied with uniform distribution. This phenomenon is caused by force chain transmission along the skewing direction. Moreover, the skewing depth of force chain at the contact surface significantly increases, while force chain at miscellaneous fill channel is relatively weak, forming a triangular distribution. The mutual embedding phenomenon can be observed at 10,000 time steps, and force chain is fully developed. Force chains at miscellaneous fill channel connect and form an arc distribution that opens upward. The force chain at the upper position of the channel is still weak. Therefore, particles at the contact surface initially develop downward deformation, thus causing dislocation of particles at two sides and producing a skewed force chain. The skewed force chain continuously develops, and force chains at miscellaneous fill channel will be connected after reaching a certain extent, forming arch force chains. Particles above the arc force chains move upward due to the weak force chains and are influenced by the dislocation of surrounding particles.

\section{Comparison and Validation}

Figure $10(\mathrm{~b})$ shows that the soft soil particles have been squeezed into the miscellaneous fill channel, and the thickness of the soft soil particles in each miscellaneous fill channel is not different, which is similar to laboratory the test rule (Figure 10(a)). The results show that the numerical model is reasonable and can reflect the general law of the embedded displacement.

It can be seen from Figure 11 that the growth rate of embedded displacement with load in numerical simulation is slightly slower than that of laboratory test results. Under the load of $50 \mathrm{kPa}$, the embedded displacement of laboratory test and numerical simulation is approximately equal. 


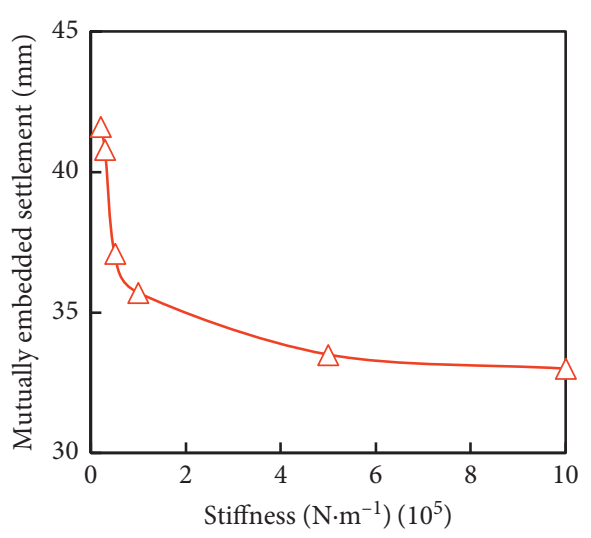

(a)

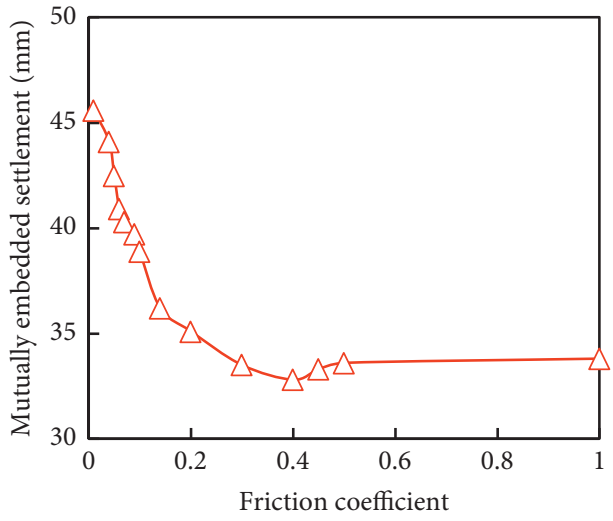

(b)

FiguRE 5: Relation curves of mutually embedded settlement with contact stiffness and friction coefficient. (a) Relation curves between mutually embedded settlement and contact stiffness. (b) Relation curves between mutually embedded settlement and friction coefficient.

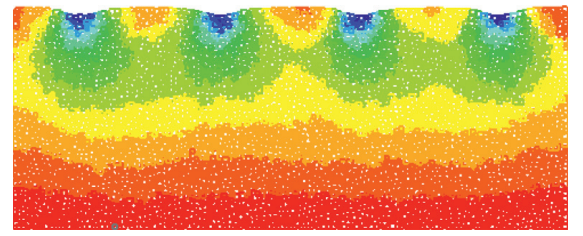

(a)

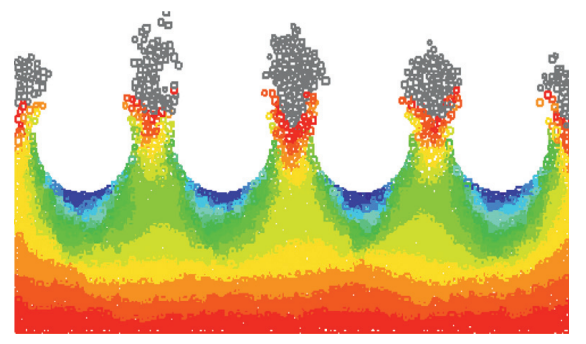

(c)

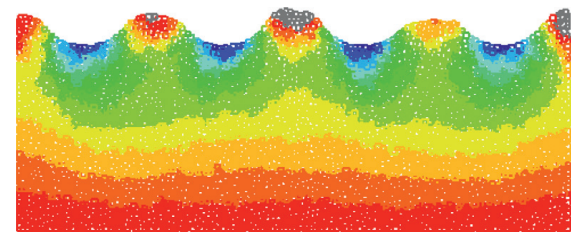

(b)

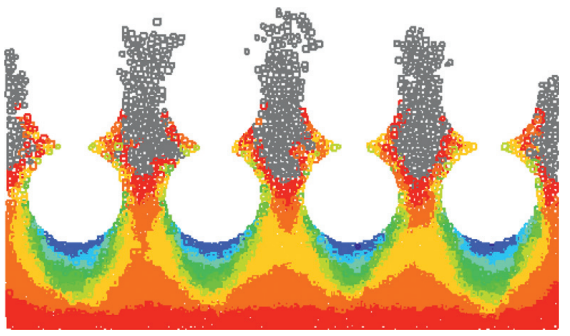

(d)

Figure 6: Vertical displacement of particles at different time steps. (a) Cloud chart of particle displacement at 2500 time steps. (b) Cloud chart of particle displacement at 5000 time steps. (c) Cloud chart of particle displacement at 10,000 time steps. (d) Cloud chart of particle displacement at 15,000 time steps.

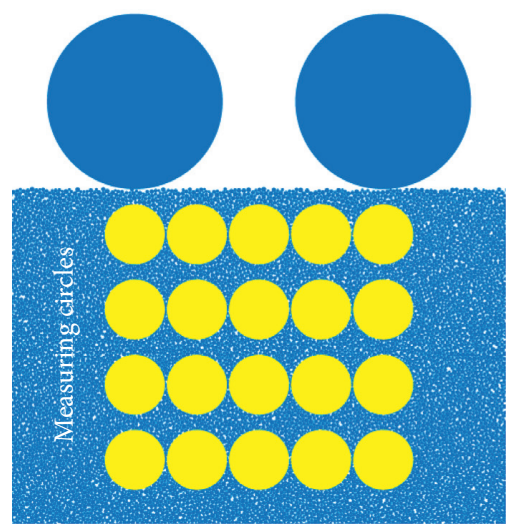

FIGURE 7: Layout of measuring circles. 


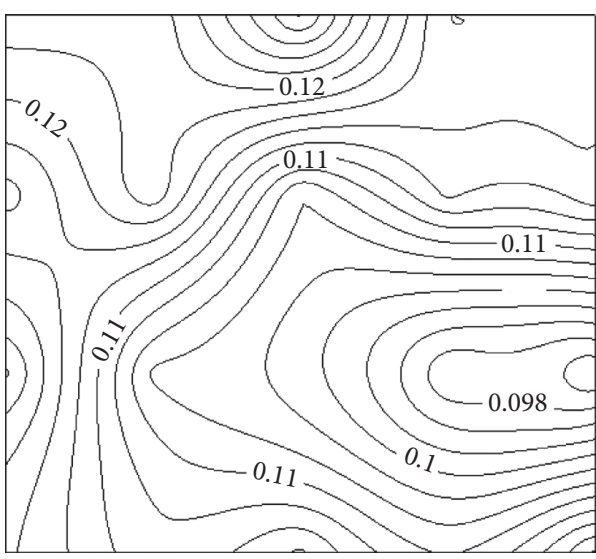

(a)

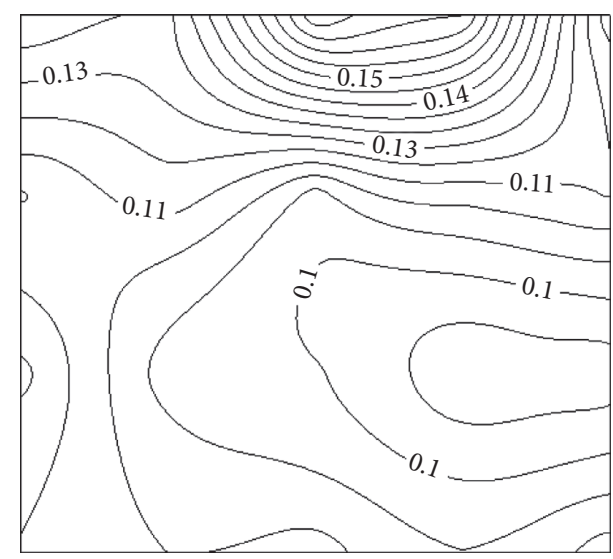

(b)

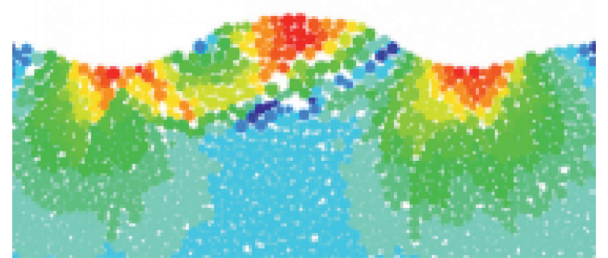

(c)

FIGURE 8: Contour line of porosity in soft soil particles. (a) Contour line of porosity at 2500 time steps. (b) Contour line of porosity at 7500 time steps. (c) Position state of particles at 10,000 time steps.

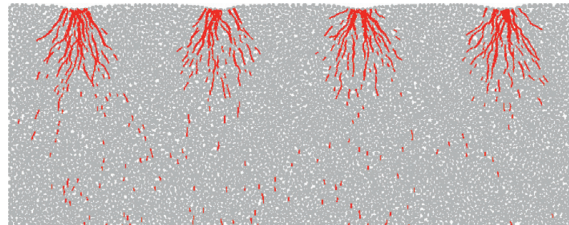

(a)

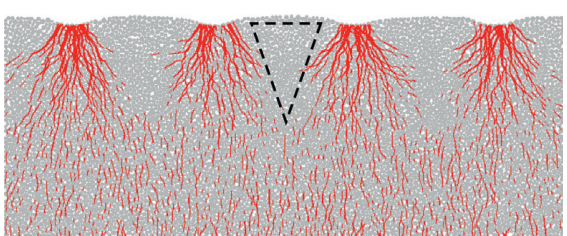

(b)

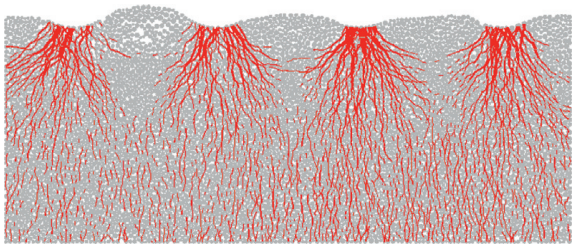

(c)

FIGURE 9: Intraparticle force chain distribution at different time steps. (a) Intraparticle force chain distribution at 2500 time steps. (b) Intraparticle force chain distribution at 5000 time steps. (c) Intraparticle force chain distribution at 10,000 time steps. 


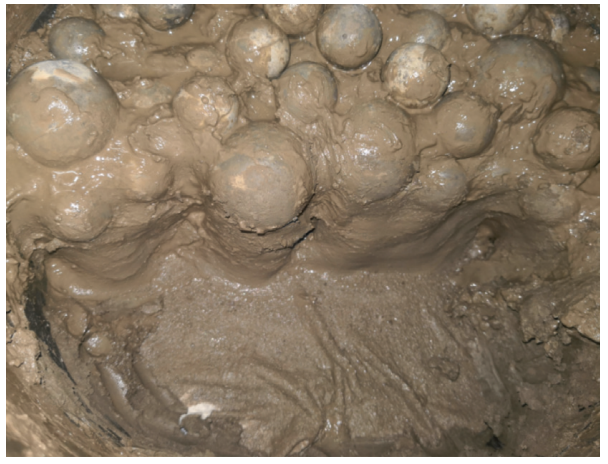

(a)

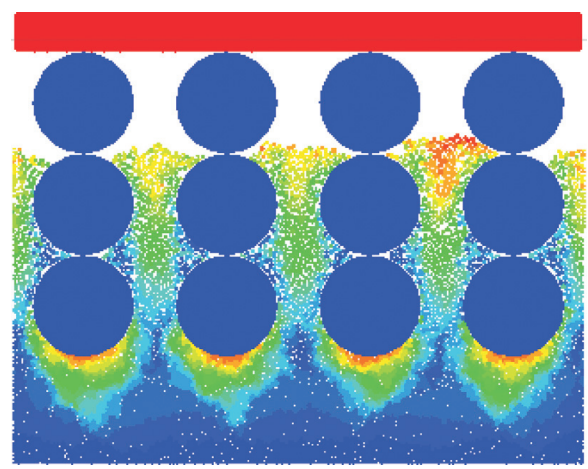

(b)

FIGURE 10: Comparison between numerical and test results: (a) test results with $100 \mathrm{kPa}$ external loading; (b) numerical results with $100 \mathrm{kPa}$ external loading.

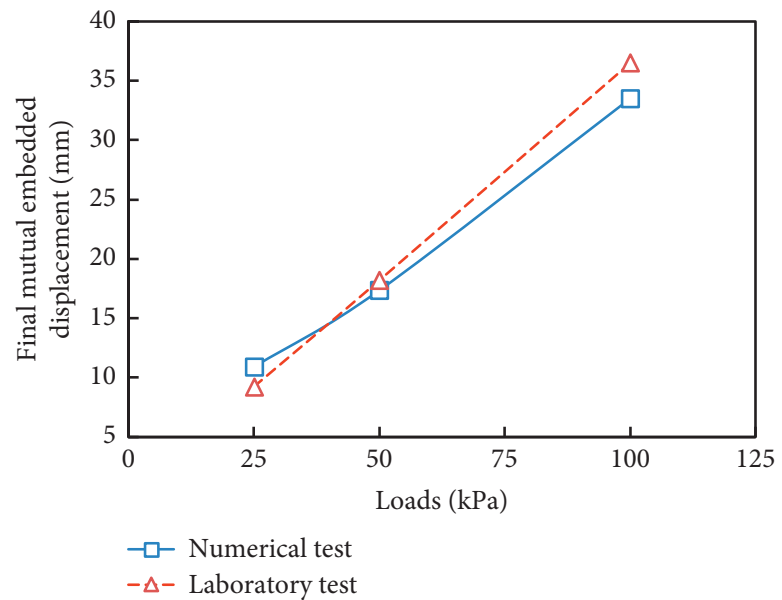

FIGURE 11: Comparison between numerical and laboratory test.

\section{Conclusions}

In this study, a two-dimensional numerical simulation of mutually embedded settlement of miscellaneous fill-soft soil composite foundation is conducted by using the particle flow method. Influences of microparameters of particles on mutually embedded settlement are investigated, and influencing laws of controlling factors of mutual embedding phenomenon are discussed. The following major conclusions could be drawn.

(1) Mutually embedded settlement decreases first and then stabilizes with the increase in friction coefficient. This settlement attenuates continuously with the increase in normal stiffness. Mutually embedded settlement continuously decreases when the maximum static friction force on the interface approaches the interparticle maximum static friction force.

(2) Mutual embedding phenomenon is the consequence of relative movement between soft soil and miscellaneous fill particles. Under loads, miscellaneous fill particles produce concentrated stress on soft soil particles. Loads in the early stage are insufficient to overcome interparticle friction, and particles hardly produce dislocation, thus leading to slight changes in porosity. With the further transmission of loads, particles at the contact surface become tight and squeeze the surrounding particles. As a result, particles at miscellaneous fill channel slide upward, and porosity in the miscellaneous fill channel increases accordingly.

(3) The force chain at the contact surface inclines around, and that at miscellaneous fill channel presents approximately horizontal distribution. Particles on the contact surface move downward, and the lateral pressure on particles at the miscellaneous fill channel continuously increases. The contact force direction continuously changes, and then arch force chains are formed after reaching to a certain extent.

\section{Data Availability}

The data used to support the findings of this study are available from the corresponding author upon request. 


\section{Conflicts of Interest}

The authors declare that there are no conflicts of interests regarding the publication of this paper.

\section{Acknowledgments}

This research was financially supported by the National Natural Science Foundation of China (no. 51778211), the Natural Science Foundation of Jiangsu Province (grant no. BK20171434), and the Fundamental Research Funds for the Central Universities (grant no. B200204036).

\section{References}

[1] W.-J. Xu and R.-L. Hu, "Conception, classification and significations of soil-rock mixture," Hydrogeology \& Engineering Geology, vol. 36, no. 4, pp. 50-51, 2009.

[2] G. Dondi, A. Simone, V. Vignali, and G. Manganelli, "Numerical and experimental study of granular mixes for asphalts," Powder Technology, vol. 232, no. 4, pp. 31-40, 2012.

[3] D. Liu, Z. Gu, R. Liang et al., "Impacts of pore-throat system on fractal characterization of tight sandstones," Geofluids, vol. 2020, no. 9, 17 pages, Article ID 4941501, 2020.

[4] J. Xia, R. Hu, S. Qi et al., "Large-scale triaxial shear testing of soil rock mixtures containing oversized particles," Chinese Journal of Rock Mechanics \& Engineering, vol. 36, no. 8, pp. 2031-2039, 2017.

[5] Q. Meng, H. Wang, M. Cai, W. Xu, X. Zhuang, and T. Rabczuk, "Three-dimensional mesoscale computational modeling of soil-rock mixtures with concave particles," Engineering Geology, vol. 277, p. 105802, 2020.

[6] X. Wang, C. Liu, S. Chen et al., "Impact of coal sector's decapacity policy on coal price," Applied Energy, vol. 265, Article ID 114802, 2020.

[7] Q.-X. Meng, D. Lv, and Y. Liu, "Mesoscale computational modeling of concrete-like particle-reinforced composites with non-convex aggregates," Computers \& Structures, vol. 240, p. 106349, Article ID 106349, 2020.

[8] C. Zhu, M. He, M. Karakus, X. Cui, and Z. Tao, "Investigating toppling failure mechanism of anti-dip layered slope due to excavation by physical modelling," Rock Mechanics and Rock Engineering, vol. 53, no. 11, pp. 5029-5050, 2020.

[9] Q.-X. Meng, W.-Y. Xu, H.-L. Wang, X.-Y. Zhuang, W.-C. Xie, and T. Rabczuk, "DigiSim-an open source software package for heterogeneous material modeling based on digital image processing," Advances in Engineering Software, vol. 148, Article ID 102836, 2020.

[10] Q. X. Meng, H. L. Wang, W. Y. Xu, and M. Cai, “A numerical homogenization study of the elastic property of a soil-rock mixture using random mesostructure generation," Computers and Geotechnics, vol. 98, pp. 48-57, 2018.

[11] T. L. T. Zhan, Y. M. Chen, and W. A. Ling, "Shear strength characterization of municipal solid waste at the Suzhou landfill, China," Engineering Geology, vol. 97, no. 3, pp. 97-111, 2007.

[12] X. Wen-Jie, X. Qiang, and H. Rui-Lin, "Study on the shear strength of soil-rock mixture by large scale direct shear test," International Journal of Rock Mechanics and Mining Sciences, vol. 48, no. 8, pp. 1235-1247, 2011.

[13] A. Bagherzadeh-Khalkhali and A. A. Mirghasemi, "Numerical and experimental direct shear tests for coarse-grained soils," Particuology, vol. 7, no. 1, pp. 83-91, 2009.
[14] C. Zhu, X. Xu, W. Liu et al., "Softening damage analysis of gypsum rock with water immersion time based on laboratory experiment," IEEE Access, vol. 7, pp. 125575-125585, 2019.

[15] Q.-X. Meng, H. Wang, M. He, J. Gu, J. Qi, and L. Yang, "Displacement prediction of water-induced landslides using a recurrent deep learning model," European Journal of Environmental and Civil Engineering, pp. 1-15, 2020.

[16] Q. Meng, H. Wang, W. Xu, and Q. Zhang, "A coupling method incorporating digital image processing and discrete element method for modeling of geomaterials," Engineering Computations, vol. 35, no. 1, pp. 411-431, 2018.

[17] Y. R. Zhao, Q. Xie, G. L. Wang, Y. J. Zhang, Y. X. Zhang, and W. Su, "A study of shear strength properties of municipal solid waste in Chongqing landfill, China," Environmental Science and Pollution Research, vol. 21, no. 22, pp. 1260512615, 2014.

[18] J. K. Thakur and J. Han, "Recent development of recycled asphalt pavement (RAP) bases treated for roadway applications," Transportation Infrastructure Geotechnology, vol. 2, no. 2, pp. 68-86, 2015.

[19] J. Wang, W. Cao, Y. Zhai et al., "Horizontal push-shear test of soil-rock mixture filled foundation under different water environments," Journal of Central South University, vol. 47, no. 2, pp. 615-620, 2016.

[20] X. W. Tang, Z. C. Ma, and Z. Q. Li, "Numerical analysis on consolidation settlement of soft soil foundation for artificial island," Advanced Materials Research, vol. 531, no. 531, pp. 324-328, 2012.

[21] C. Zhu, Z. Yan, Y. Lin et al., "Design and application of a monitoring system for a deep railway foundation pit project," IEEE Access, vol. 7, pp. 107591-107601, 2019.

[22] M. Zhang, J. J. Li, and C. K. Qin, "Analysis and discussion on post-construction settlement of soft soil foundation treatment test section of highway," IOP Conference Series: Earth \& Environmental Science, vol. 81, Article ID 012151, 2017.

[23] G. X. Cao, E. X. Song, and X. U. Ming, "Simplified calculation methods of post-construction settlement of high-fill foundation in mountain airport," Rock \& Soil Mechanics, vol. 32, pp. 1-5+26, 2011.

[24] P. Yang, "Finite element analysis of settlement of soft soil foundation under reservoir dam," Journal of Engineering Geology, vol. 16, no. 4, pp. 533-538, 2008.

[25] H. Pan, D. Yin, N. Jiang, and Z. Xia, "Crack initiation behaviors of granite specimens containing crossing-double-flaws with different lengths under uniaxial loading," Advances in Civil Engineering, vol. 2020, no. 2, 13 pages, Article ID 8871335, 2020.

[26] J. R. Guo, X. C. Zheng, J. Q. Zhang, and Z. M. Zhao, "Calculation and analysis on the soft soil foundation settlement with elastic-visco-plasticity (EVP) model," Advanced Materials Research, vol. 1145, pp. 8-16, 2018.

[27] X. U. Xue-Yong, C. Guo-Hai, W. Ren et al., "Settlement calculation and analysis of embankment with squeezing thick silt by blasting," Rock and Soil Mechanics, vol. 35, no. S2, pp. 364-369, 2014.

[28] W. Li, T. Zhuo-Ying, Z. Bo-Hao et al., "Dynamic response analysis of soft foundation earth-rock dam under impact and squeezing action of silt," Rock and Soil Mechanics, vol. 35, no. 3, pp. 827-834, 2014.

[29] Y. Yi, S. Liu, A. J. Puppala, and P. Xi, "Vertical bearing capacity behaviour of single T-shaped soil-cement column in soft ground: laboratory modelling, field test, and calculation," Acta Geotechnica, vol. 12, no. 5, pp. 1077-1088, 2017. 
[30] L. Wang, "Experimental study on bearing capacity of postgrouting bored piles in deep-thick miscellaneous fill soil layer," World Earthquake Engineering, vol. 32, no. 3, pp. 28-34, 2016.

[31] M. Zheng, J. M. Yang, Z. L. Li, and M. H. Zhou, "Plate load test applied to detect bearing capacity of the miscellaneous fill subgrade reinforced by the dynamic compaction," Advanced Materials Research, vol. 1065-1069, pp. 778-782, 2014.

[32] F. Zhang, L. Zhang, W. Hong et al., "Stabilization of expansive soil with polyvinyl alcohol and potassium carbonate," Advances in Civil Engineering, vol. 2019, 2019.

[33] F. Zhang, L. Zhang, L. Yang, T. Feng, L. Chen, and X. Zhong, "The cement content measurement of cement mixing piles with EDTA titration method," KSCE Journal of Civil Engineering, vol. 22, no. 11, pp. 4306-4315, 2018.

[34] F. Zhang, L. Zhang, and Y. Li, "Investigation of gap-graded soils' seepage internal stability with the concept of void filling ratio," PLoS One, vol. 15, no. 2, Article ID e0229559, 2020.

[35] S. Zhao, T. M. Evans, and X. Zhou, "Effects of curvature-related DEM contact model on the macro- and micro-mechanical behaviours of granular soils," Géotechnique, vol. 68 , no. 12, pp. 1085-1098, 2018.

[36] Z. Shiwei, E. T. Matthew, and Z. Xiaowen, "Shear-induced anisotropy of granular materials with rolling resistance and particle shape effects," International Journal of Solids and Structures, vol. 150, pp. 268-281, 2018. 